\title{
Segregation and Overlap of Callosal and Association Neurons in Frontal and Parietal Cortices of Primates: A Spectral and Coherency Analysis
}

\author{
P. B. Johnson, ' A. Angelucci, ' R. M. Ziparo, ${ }^{1}$ D. Minciacchi, ${ }^{2}$ M. Bentivoglio, ${ }^{2, a}$ and R. Caminiti ${ }^{1}$ \\ IInstitute of Physiology, University of Rome "La Sapienza," and Institute of Neurology, Catholic University, Rome, Italy
}

The spatial relations between selected classes of association and callosal neurons were studied in the frontal and parietal lobes of the macaque monkey using retrogradely transported fluorescent dyes. Fast blue and nuclear yellow were injected in the left frontal (areas 4 and 6) and right posterior parietal (area 5) cortices, respectively. These injections led to the retrograde labeling, in the right frontal cortex, of callosal neurons projecting homotopically and association neurons projecting to ipsilateral area 5; in the left superior parietal lobule, of callosal neurons projecting to contralateral area 5 and association neurons projecting to the ipsilateral frontal lobe. In both frontal and parietal cortices, callosal and association neurons were located in layers III and V-VI; a few neurons were also found in layer II. The contribution of layers V-VI to the callosum was significantly higher in areas 4 and 6 than in area 5 . Only a small number of neurons (less than $1 \%$ ) were double labeled.

Spectral analyses were used to characterize the spatial periodicities of the distributions of callosal and association neurons. In areas 4,6 , and 5 , both association and callosal spectra were dominated by a strong elevation in the range of low spatial frequencies, corresponding to periodicities in cell density with a peak-to-peak distance of about $8 \mathrm{~mm}$. This indicated an arrangement of these corticocortical cells in the form of bands. The latter displayed various shapes and orientations and were composed of more discrete assemblies of cell clusters of about $400-1000 \mu \mathrm{m}$ width. Their presence was revealed in the power spectra by a small elevation in the range of high spatial frequencies.

The coherency analysis assessed the degree of linear relationships for each spatial frequency, and therefore the degree of similarity, between callosal and association cell distributions, together with their phase relations. Little coherency was found in areas 4 and 6 between bands of callosal and association neurons, which suggests that the 2 cell populations are differently and independently distributed in the tangential domain, with no simple phase relations. The overall mean coherency was higher in area 5 than in the

\footnotetext{
Received June 6, 1988; revised Sept. 16, 1988; accepted Sept. 20, 1988.

This work was supported by grants from the Consiglio Nazionale delle Ricerche and from the Ministero della Pubblica Istruzione, Rome, Italy. We thank Prof. A. Urbano for his support and encouragement.

Correspondence should be addressed to Roberto Caminiti, Istituto di Fisiologia Umana, Facoltá di Medicina e Chirurgia, Universitá di Roma "La Sapienza," P. le A. Moro 5, 00185 Roma, Italy.

"Present address: Istituto di Anatomia ed Istologia, Facoltá di Medicina e Chirurgia, Universitá degli Studi, Strada le Grazie, 37134 Verona, Italy.

Copyright (C) 1989 Society for Neuroscience $0270-6474 / 89 / 072313-14 \$ 02.00 / 0$
}

frontal cortex: callosal and association bands were more similar in shape, with more extensive zones of overlap. These data indicate that callosal and association neurons share common principles of spatial organization despite the great regional variability of their interrelations in the tangential cortical domain.

The uneven distribution of callosal and association neurons determines the existence in the frontal and parietal cortices of efferent zones in which a transformation of the original cortical information takes place. The transformations occurring in the callosal and association outputs of these areas are of relevance for the interhemispheric transfer of motor habits and the interplay of frontal and parietal cortices in the control of motor behavior.

The distribution of the cells of origin of corticocortical pathways is nonuniform in both the radial and the tangential domains. The radial selectivity of cortical efferent cells, and of other cortical cells (Rakic, 1974), rests on their time of origin and rate of migration. Many studies indicate that a particular tangential location is achieved during development from an early exuberant distribution (Innocenti et al., 1977; Innocenti and Caminiti, 1980; Chow et al., 1981; Ivy and Killackey, 1982; Feng and Brugge, 1983; Innocenti and Clarke, 1984; Killackey and Chalupa, 1986). The uneven distribution of efferent neurons, together with the systematic variation of functional propcrties across the tangential cortical domain, allows only selected information to be part of a given efferent message. The most striking example is the distribution of the cells of origin of the corpus callosum in primary sensory and motor areas (see Innocenti, 1986, for a review). The preferential location of callosal neurons at the "midline representations" of these areas (Berlucchi, 1981; Innocenti, 1986) provides the substrate for the interhemispheric unification of right and left worlds. This is necessary for the unity of sensory and perceptual experiences (see Berlucchi, 1981, for a review). Despite this uniqueness, however, in the more general context of corticocortical connectivity there is no a priori reason to believe that the rules governing callosal and association pathways are different. Anatomical (Caminiti et al., 1985) and physiological (Hubel and Wiesel, 1967; Gross and Mishkin, 1977; Innocenti, 1980) studies support a basic similarity between these 2 sets of connections. Developmental considerations point to the same conclusion (Innocenti, 1986). The organization of the sources and sinks of these pathways may represent a substrate of their similarity. Anatomical studies in the monkey indicate that the terminations in different cortical areas of callosal (Jones et al., 1975; Shanks 

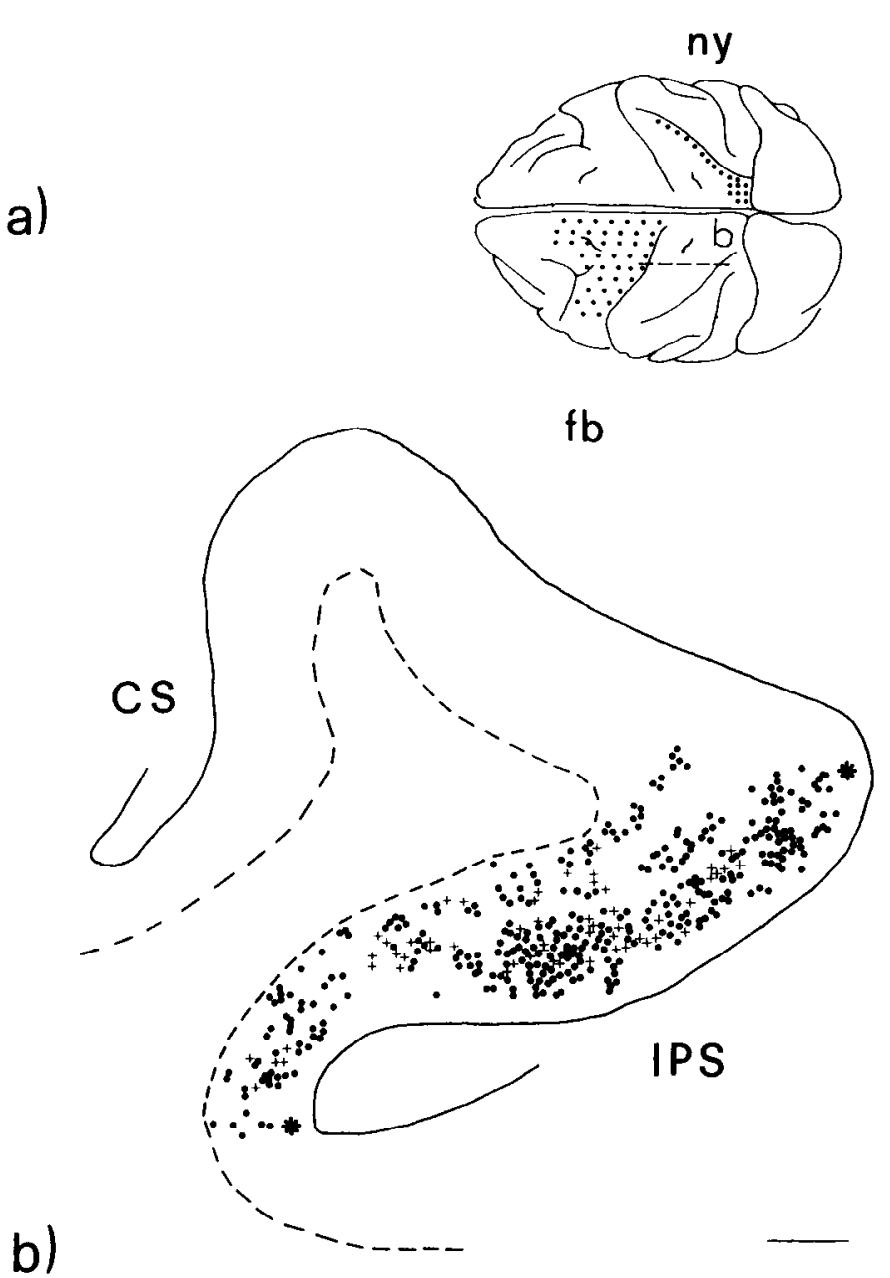

Figure 1. a, Brain figurine with injection grids. FB and NY were injected in areas 4 and 6 of the left hemisphere and in area 5 of the right hemisphere. Dots indicate the needle penetrations. $b$, Distribution of callosal (crosses) and association (dots) neurons in a representative sagittal section of area 5, at the level indicated by the broken line in $a$. Asterisks represent alignment points used for flattening the section. $I P S$, intraparietal sulcus; $C S$, central sulcus. Calibration bar, $1 \mathrm{~mm}$.

et al., 1975; Kunzle, 1976; Goldman and Nauta, 1977; Rockland and Pandya, 1979; Fitzpatrick and Imig, 1980; Caminiti and Sbriccoli, 1985; see, however, Killackey et al., 1983) and association (Jones et al., 1975; Goldman and Nauta, 1977; WongRiley, 1979; Rockland and Pandya, 1979; Goldman-Rakic and Schwartz, 1982) fibers is stripe-like. In some fields these callosal and association terminal stripes interdigitate (Jones et al., 1979; Goldman-Rakic and Schwartz, 1982). In other fields, as in the visual cortex (Zeki, 1978; Van Essen et al., 1982), overlap of callosal and association terminal fields seems to be the rule. The cells of origin of these sets of fibers show a more complex pattern of tangential distribution. From the qualitative point of view (also depending on the sensitivity of tracers used), waxing and waning, patchy, columnar, and striped patterns have been described. Quantitative studies, with spectral analysis (Caminiti et al., 1985), have revealed a stripe-like organization formed by more discrete periodicities of "columnar" type. In these reports (Caminiti et al., 1985, 1988b) the spatial arrangement of selected classes of parietal callosal neurons was compared with that of frontoparietal association neurons. However, the reciprocal spa- tial relationships between callosal and association "stripes" and "columns" in the same area cannot be investigated with a single tracer. To date there are excellent qualitative studies in the prefrontal cortex and area 7 (Schwartz and Goldman-Rakic, 1984; Andersen et al., 1985), but quantitative analyses of this important aspect of cortical organization are still lacking.

We adopted a retrograde double-labeling strategy for the identification of callosal and association neurons in the frontal and posterior parietal cortices. The quantitative evaluation and comparison of their distributions were based on spectral and coherency analyses. The spectral analysis provides an accuratc description of the periodic fluctuations in the density of efferent cells in the tangential cortical domain as well as a definition of the relative importance of these fluctuations. The coherency analysis compares 2 different distributions for desired ranges of periodicities, expressing the degree to which they are linearly related and providing their phase relationships. This analysis allows a detailed description of the relative locations of callosal and association tangential cell distributions and an objective estimate of their degree of similarity.

\section{Materials and Methods}

The experiments were performed on 2 adult Macaca fascicularis monkeys. The animals were anesthetized with sodium pentobarbital $(40 \mathrm{mg} /$ $\mathrm{kg}$; i.p.). Surgery was performed under aseptic conditions. A craniotomy was first performed over the frontal lobe of the left hemisphere and 39 injections of Fast blue (FB, Illing; 5\% in sterile saline) with multiple release sites $(0.8 \mu \mathrm{l}$ each) were made throughout areas 4 and 6 with a $10 \mu \mathrm{l}$ microsyringe (Fig. $1 a$ ). After $49 \mathrm{~d}$, a second craniotomy was performed over the parietal lobe of the right hemisphere and 20 injections of nuclear yellow (NY, Illing; $1 \%$ in sterile saline) with multiple release sites $(0.3 \mu \mathrm{l} \mathrm{each})$ were made in area 5 of the superior parietal lobule (SPL; Fig. 1a). The injections were generally spaced $2.5 \mathrm{~mm}$ apart in the tangential domain and were aimed at ensuring a uniform distribution of tracer. Multiple release sites were used at different depths (every $2 \mathrm{~mm}$ ) to inject the cortex buried in the banks of sulci. The injection grids led to a local distribution of dye generally consisting of dense central cores surrounded by halos of diffusion. The halos of adjacent injections were always overlapping; in addition, overlap of central cores was often observed. Three days after the NY injections, the animals were again anesthetized and perfused with saline followed by buffered $12 \%$ formalin. Upon removal, the brains were cut in blocks and stored in a solution of $30 \%$ buffered sucrose until they sank (approximately $3 \mathrm{~d}$ ). The brain blocks were cut on a freezing microtome at 40 $\mu \mathrm{m}$. Every third section was mounted on slides, air dried, and coverslipped with Entellan. Adjacent sections were stained with cresyl violet. The unstained sections were studied with a Leitz fluorescence microscope using $360 \mathrm{~nm}$ and $390 \mathrm{~nm}$ excitation wavelengths.

The injections of fluorescent dyes in the frontal and parietal cortices resulted in retrograde labeling of the following populations of corticocortical neurons: in the frontal cortex (areas 4 and 6), callosal neurons projecting homotopically to the contralateral frontal cortex (frontal callosal neurons) and association cells projecting to ipsilateral area 5 (frontoparietal association neurons); in the parietal cortex (area 5), association neurons projecting to the ipsilateral frontal cortex (parietofrontal association neurons) and callosal cells projecting homotopically to contralateral area 5 (parietal callosal neurons). The cells of origin of heterotopic callosal connections were not considered in this study.

Data analysis. The distribution of retrogradely labeled neurons was plotted at regular intervals $(240 \mu \mathrm{m})$ in areas 4 and 6 of the right hemisphere and area 5 of the left hemisphere. The microscope stage was connected through potentiometers to a PDP $11 / 23+$ minicomputer. Two-dimensional (2-D) flattened reconstructions of frontal and parietal cortices were generated using a modified version of a method described elsewhere (Innocenti, 1980; Caminiti et al., 1985). Briefly, the position of each individual labeled cell in the tangential cortical domain was computed using a radial segmentation scheme. The labeled cells contained in each section were projected onto a reference line running parallel to the pial surface at a depth constantly proportional to the distance between this and the bottom of layer VI. This projection was 


\begin{tabular}{|c|c|c|c|c|c|c|c|}
\hline \multicolumn{4}{|c|}{ Frontal cortex (areas 4,6) } & \multicolumn{4}{|c|}{ Parietal cortex (area 5) } \\
\hline Number & $\begin{array}{l}\text { Supra- } \\
\text { granular }\end{array}$ & $\begin{array}{l}\text { Infra- } \\
\text { granular }\end{array}$ & Ratio & Number & $\begin{array}{l}\text { Supra- } \\
\text { granular }\end{array}$ & $\begin{array}{l}\text { Infra- } \\
\text { granular }\end{array}$ & Ratio \\
\hline \multicolumn{4}{|c|}{ Frontoparietal association cells } & \multicolumn{4}{|c|}{ Parietofrontal association cells } \\
\hline 62,234 & $\begin{array}{l}45,624 \\
(73.3 \%)\end{array}$ & $\begin{array}{l}16,610 \\
(26.7 \%)\end{array}$ & 2.74 & 15,511 & $\begin{array}{l}10,581 \\
(68.2 \%)\end{array}$ & $\begin{array}{l}4,930 \\
(31.8 \%)\end{array}$ & 2.14 \\
\hline \multicolumn{4}{|c|}{ Callosal cells } & \multicolumn{4}{|l|}{ Callosal cells } \\
\hline 16,876 & $\begin{array}{c}8,727 \\
(51.7 \%)\end{array}$ & $\begin{array}{c}8,149 \\
(48.3 \%)\end{array}$ & 1.07 & 7,298 & $\begin{array}{l}6,061 \\
(83.1 \%)\end{array}$ & $\begin{array}{l}1,237 \\
(16.9 \%)\end{array}$ & 4.89 \\
\hline
\end{tabular}

guided by segments mimicking the radial arrangement of cell bodies in the cortex. The latter was divided into radial sectors, and the tangential position of each cell was determined by the sector into which it fell and by its position within that sector. The reference line was then flattened and divided into $160-\mu \mathrm{m}$-wide bins. The number of cells contained in cach bin was expressed by arrayed vertical segments of proportional length. Sections were finally aligned on common reference points.

The purpose of the quantitative analysis was twofold: to quantify the periodic nature of the fluctuations in cell densities evident in the flattened reconstructions, and to study the spatial relationships between patterns of different cell populations. Standard spectral analysis procedures were used to address the first objective, while coherency analysis techniques were introduced to investigate the spatial relationships between different cell populations. The binned cell counts along the rostrocaudal dimension of each section were used for the quantitative analyses. Histograms of cell numbers versus tangential location were computed for each population (callosal and association) in each section by counting the number of cells in $160-\mu \mathrm{m}$-wide bins. The bin size was chosen to maximize the number of cells per bin while maintaining sufficient spatial resolution to investigate fluctuations in cell number with peak-to-peak distances of around $1 \mathrm{~mm}$.

The distribution of cells in a section can be divided into components which vary regularly and repeatedly in space. These varying components can be characterized by their amplitude and their peak-to-peak distances (periods). Spectral analysis, the formalization of this decomposition process, facilitates the identification of the periodic content of a distribution. The spectral analysis techniques employed here have been described in detail elsewhere (Caminiti et al., 1985, 1988b; see Appendix for a brief description).

The double-labeling strategy of our experiments allowed not only the spectral analysis of the 2 labeled cell populations independently but also the analysis of their mutual relationships in the same sections. "Coherency" is a frequency domain measure of the degree of similarity of 2 distributions in space. $\Lambda t$ a given Fourier frequency, the periodic components of 2 distributions that overlap in space may be either perfectly aligned or out of phase to varying degrees. Phase is the measure of shift between 2 sinusoids of equal frequency. The shapes of 2 distributions are very similar and the coherency value approaches 1 when their periodic components have similar phases throughout a given band of frequency. If, on the other hand, the phases are not coherent but vary widely, the coherency value in that range of frequencies is near zero. It follows that for bands of frequencies with low coherency the actual value of the phase between the 2 distributions is meaningless. However, for high values of coherency the phase between the 2 distributions is relatively constant and expresses how they are located in space in relation to one another.

The results of the coherency analysis were thus expressed in 2 plots: coherency and phase as a function of Fourier frequency. We were interested in the portions of the frequency domain that exhibit high values of coherency. Therefore, we followed the standard practice of using the squared coherency, which deemphasizes low values. Squared coherency varied between zero and 1 , and the phase varied between $-\pi$ and $\pi$. A detailed description of the procedures used to calculate the squared coherency and phase is given in the Appendix.

\section{Results}

\section{Laminar distribution of callosal and association neurons in} the frontal and parietal cortices

The results obtained were very similar in the 2 animals and were based on the localization in the cortex of over 200,000 labeled cells. Both qualitative and quantitative observations indicated little interanimal variability.

The radial distribution of callosal and association neurons was uneven in both the frontal and parietal cortices (Figs. 1, 2). In the frontal cortex (Fig. 2, left), callosal neurons were mainly medium-sized and large pyramidal cells of layers III, V, and VI; a few small pyramids were labeled in layers II and IV. Association neurons were present in the same layers; in layer III they were located more superficially than were the callosal neurons.

The quantitative analysis (Table 1) showed that in areas 4 and 6 the main difference between these 2 cell populations was in the relative contributions of supragranular (II-III) and infragranular (V-VI) layers. [We use the terms supra- and infragranular layers for descriptive purposes only. A typical granular layer (IV) is in fact absent in the frontal cortex.] The ratio of supragranular to infragranular cells was 2.74 for the frontoparietal association population and 1.07 for the frontal callosal population. This finding indicates that in the frontal cortex association connections originate mainly from supragranular layers whereas callosal connections originate in equal amounts from both supra- and infragranular layers.

In the parietal cortex (Fig. 2, right), callosal and association cells were pyramidal cells of layers III, V, and VI; few of them were found in laminae II and IV. The ratio of supragranular to infragranular cells was 2.14 for the parietofrontal association cells, which was similar to that observed for the frontoparietal population. The ratio for parietal callosal cells, however, was 4.9 , indicating that, contrary to the case in the frontal cortex, the infragranular parietal layers contributed more to the parietofrontal association connection than to the parietal callosal connection. The supragranular layers contributed at least twice as much as did the infragranular layers to the frontoparietal and parietofrontal cell populations. These data indicate that the callosum receives a greater contribution from the infragranular layers of the frontal cortex than from those of area 5. Furthermore, our finding of a regional variability in the laminar distribution of callosal cells raises interesting questions about the 

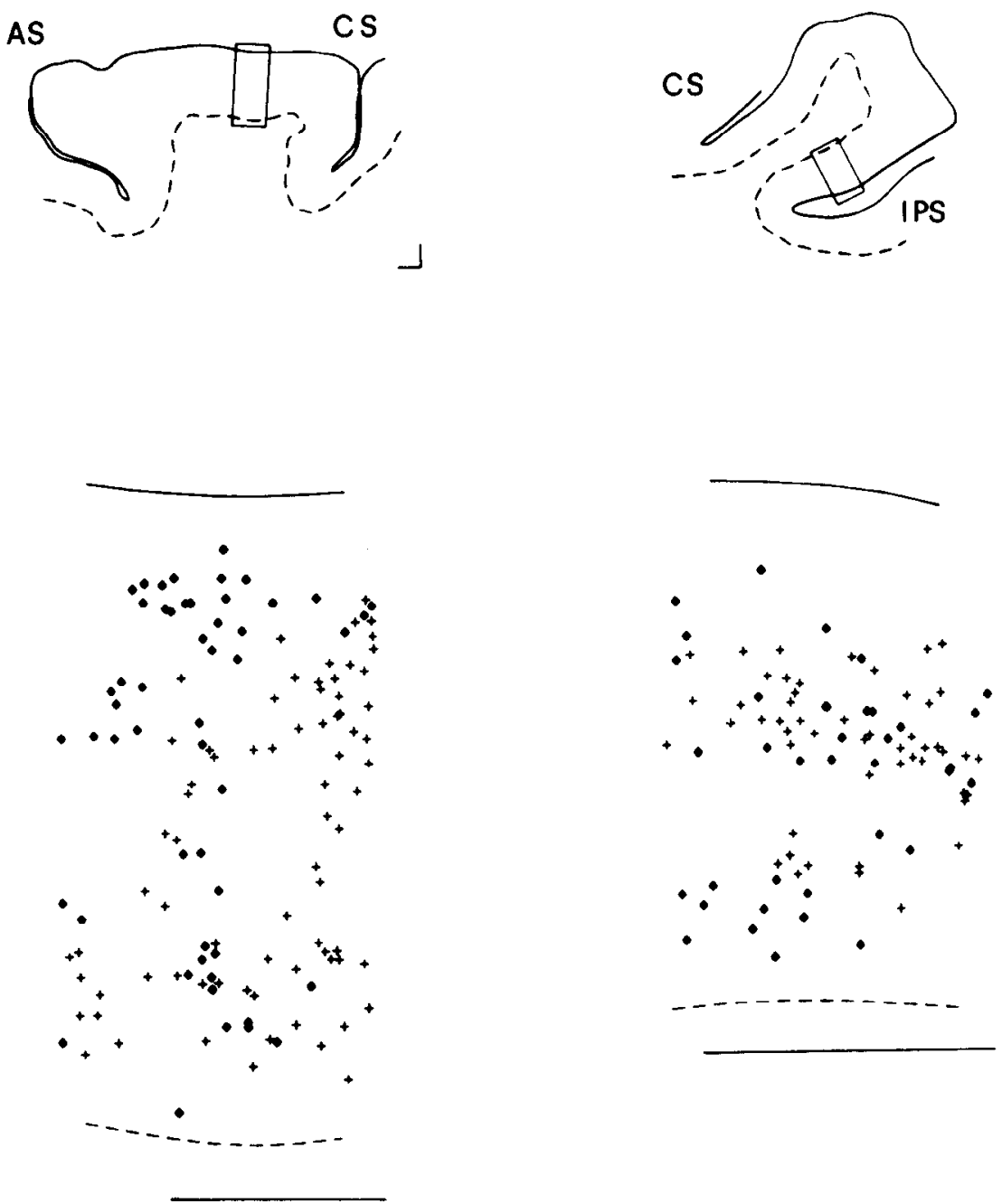

Figure 2. Radial distribution of callosal (crosses) and association (diamonds) cells in 2 representative probes of cortex from areas 4 (left) and 5 (right), as indicated in the insets of the sections. $A S$, arcuate sulcus; $C S$, central sulcus; $I P S$, intraparietal sulcus. Calibration bars, $1 \mathrm{~mm}$. nature of interhemispheric messages originating in similar layers of different cortical areas.

\section{Tangential distribution of callosal and association neurons}

An example of the tangential distribution of callosal and association neurons and their spatial relationships is given in Figure 1 for a representative section of area 5. Both neuronal populations occupied most of the rostrocaudal extent of this area. Their distributions waxed and waned in periodic fashion and there were no simple phase relations between them. These complex spatial relationships were analyzed on 2-D maps of the cell distributions.
Frontal cortex. The location of frontal (homotopical) callosal cells and frontoparietal association cells was selective in the tangential domain (Fig. 3A). At lateral levels, callosal cells occupied almost the entire rostrocaudal extent of the frontal lobe, from the cortex of the more superficial part of the posterior bank of the arcuate sulcus (AS; area 6) to that buried in the rostral bank of the central sulcus (CS; area 4). This region, which contains the representations of orofacial structures (Woolsey et al., 1950; Clark and Luschei, 1974; Muakkassa and Strick, 1979; McGuinnes et al., 1980; Sessle and Wiesendanger, 1982; Gould et al., 1986; Matelli et al., 1986), was devoid of frontoparietal association neurons. Gould et al. (1986) described in the owl

Figure 3. Two-dimensional flattened reconstructions of the tangential distributions of callosal (green) and association (red) cells in $A$, layers IIIII of frontal areas 4 and $6 ; B$, layers V-VI of the same areas; $C$ and $D$, layers II-VI and II-III of the parietal (area 5 ) cortex. For the generation of these maps, labeled neurons in layers II-III and/or V-VI of each section were projected onto a reference line running parallel to the pial surface at a depth constantly proportional to the distance between the cortical surface and the bottom of layer VI. The line was then flattened and divided in 160- $\mu \mathrm{m}$-wide bins. The labeled cells contained in each bin were expressed as arrayed vertical segments with length proportional to their number. Sections were then aligned on common reference points (the fundus of CS in the frontal maps, the fundus of IPS in the parietal maps) and spaced $240 \mu \mathrm{m}$ apart. On each map, left is caudal, $u p$ is medial. In the frontal maps $(A$ and $B)$, sets of asterisks indicate, from left to right, the fundus of CS, its crown, the crown of the caudal bank of AS, its bottom, and (upper right) the dimple located medially to the medial limb of AS. Therefore, adjacent sets of vertically aligned asterisks demarcate, from left to right, the rostral bank of CS, the flat exposed part of the precentral gyrus, and the caudal bank of AS. Similarly, in the parietal maps $(C$ and $D)$, sets of vertically aligned asterisks represent, from left to right, the bottom of IPS and the crown of the rostral bank of IPS, so that the rostral bank of IPS is shown in the area bordered on each side by sets of asterisks. 


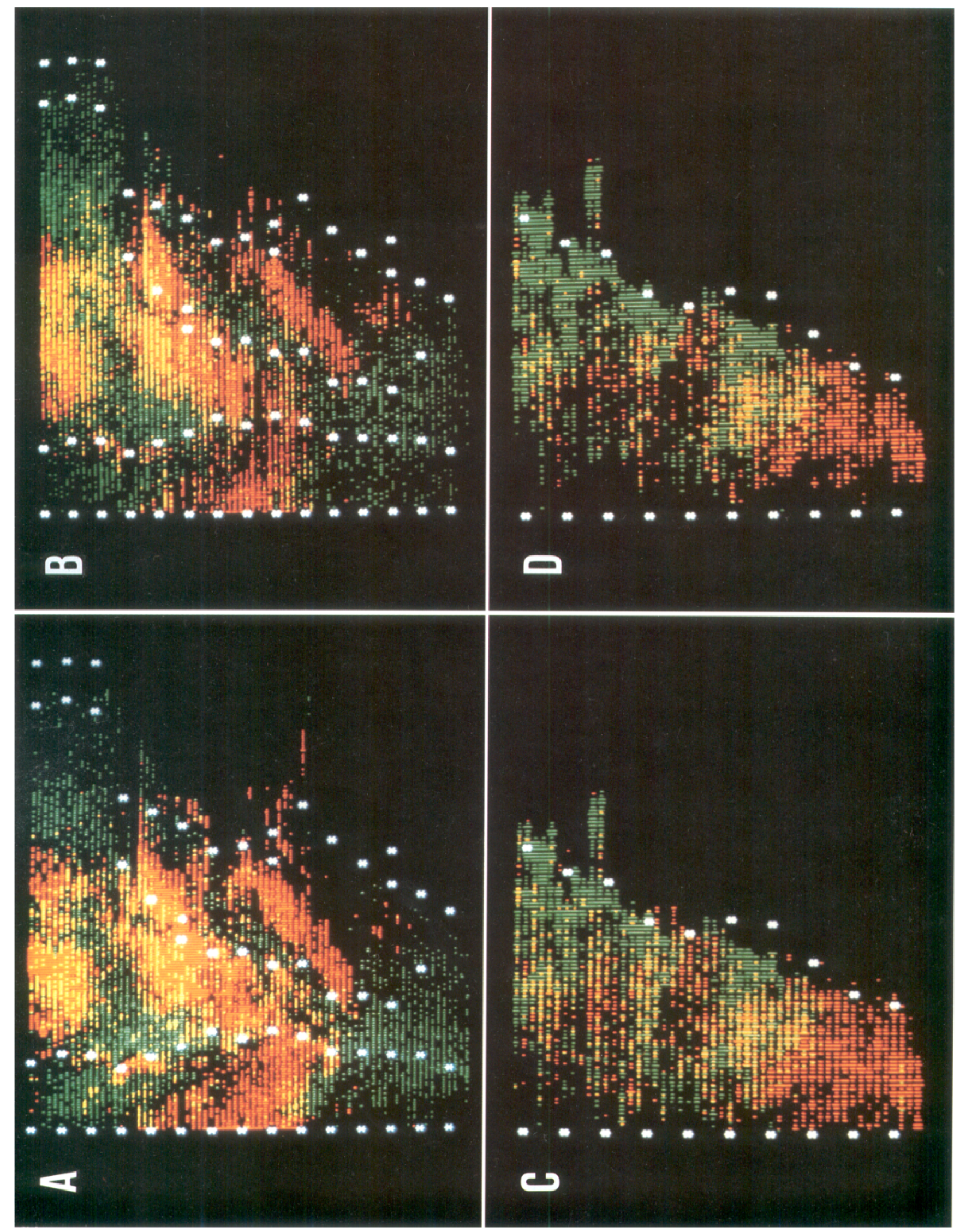


monkey an additional representation of the digits within this area. Moving medially, callosal cells gradually decreased and finally vanished from the cortex of the rostral bank of CS (area 4 ) and the exposed part of the precentral gyrus (areas 4 and 6). This region devoid of callosal neurons, which probably corresponds to part of the hand representation areas, contained instead many association neurons. At the same mediolateral levels, a band of callosal cells was clearly evident more rostrally, in the crown and upper part of the posterior bank of the inferior limb of AS (area 6). This band of callosal cells flanked a band of association neurons running from medial to lateral and from rostral to caudal. This region of the frontal lobe contains a representation of hand and arm separate from that of M1 (Matsumara and Kubota, 1979; Muakkassa and Strick, 1979; Matelli et al., 1986). The association neurons decreased towards the more medial part of the precentral gyrus and were absent in the rostral bank of CS (area 4). A dense band of labeled association cells was observed in the more posterior part of the exposed cortex (area 4) up to the crown of the posterior bank of AS (area 6). This region also contains an arm representation distinct from that of area 4 (Muakkassa and Strick, 1979). At the same mediolateral levels, callosal neurons were present throughout the rostrocaudal extent of the frontal cortex, being very numerous in the rostral' bank of CS and the exposed surface of area 4 . Medially, callosal neurons decreased in number in the rostral bank of CS and in the medial adjoining cortex. However, commissural cells were numerous in the exposed part of the precentral gyrus, in the region lying between the upper limb of AS and the edge of the hemisphere. In this part of area 6 their distribution was interrupted by a well-sculptured band of association cells. The distribution of callosal and association neurons in layers V-VI (Fig. 3B) was remarkably similar to that observed in layers II-III.

Altogether, these findings demonstrated an uneven distribution of callosal and association neurons that resulted in bands of various sizes, shapes, and orientations. These bands were mainly separate in the tangential cortical space, with only limited regions of overlap.

Parietal cortex. The distributions of callosal cells projecting homotopically and parietofrontal association neurons in area 5 are shown in the 2-D flattened reconstruction of the SPL in Figure $3 C$. In the more lateral part of area 5, association neurons spanned the rostrocaudal extent of SPL. This region containcd very few callosal neurons. Moving medially, the number of association neurons decreased, whereas that of callosal neurons increased. The latter cells formed a band throughout most of the rostrocaudal extent of the anterior bank of the intraparietal sulcus (IPS). This band merged with a second band running roughly parallel to the cytoarchitectonic border between areas 5 and 2 . At the more medial levels of area 5 , this second band curved caudally to cover most of the rostral bank of IPS. In this region, association neurons were not numerous and were scattered without any apparent pattern of distribution. The cortical regions of overlap of callosal and association neurons were of limited extent. The distribution of callosal and association neurons labeled in the infragranular layers was coextensive with that observed in the supragranular layers. The parietal map obtained from cells in layers II-III only (Fig. $3 D$ ) was very similar to that previously described.

\section{Quantitative analysis}

The number and density of frontal and parietal callosal and association cells varied in periodic fashion. The quantitative analyses performed on these cell distributions and the results obtained from a representative parietal section (Fig. 1) are shown in Figure 4. The density of callosal and association cells varied along the tangential extent of the cortex (Fig. 4a). Low- (Fig. $4 b$ ) and high- (Fig. 4c) frequency components were evidenced by appropriately filtering the histograms. The relative importance of these components was revealed by the Fourier analysis (Fig. $4, d, e$ ). The peaks in the spectra below the 20th Fourier frequency corresponded to the low-frequency components. The peaks at higher Fourier frequencies (20-25) represented the components with smaller peak-to-peak distances. This representative section showed that most of the spectral power was contained in the low-frequency range $(<20)$; therefore, the lowfrequency components were more important than the high-frequency components in determining the shapes of the cell distributions. The squared coherency (Fig. $4 f$ ) between callosal and association cell populations was relatively high in the low-frequency range $(<20)$, indicating a similarity of shape of these 2 cell distributions. In this range of low frequencies the phase was approximately zero, indicating that the 2 distributions overlapped. At higher frequencies (21-30) the squared coherency dropped to zero, reflecting dissimilarity. A second elevation was present in the squared coherency (Fig. $4 \Omega$ ) at higher Fourier frequencies (30-60). However, the value of squared coherency of this second elevation was lower than that observed in the low-frequency range. This indicates that the 2 cell populations are less similar in the high- than in the low-frequency domain. The nonzero phase indicates that the 2 populations are not perfectly overlapping in this frequency range.

Median spectra were computed for all distributions. The median estimated spectra of association and callosal cells in the frontal cortex (Fig. 5, $a, b$ ) were very similar. They showed a prominent elevation, including the first 20 Fourier frequencies ( 20 cycles $/ 41.0 \mathrm{~mm}$ ), which corresponded to periodicities in cell density with peak-to-peak distances of $8 \mathrm{~mm}$. This finding suggests an arrangement of callosal and association cells in the form of bands. In the range of shorter periodicities (i.e., higher Fourier frequencies), smaller but consistent elevations were included between Fourier frequencies 21-50. These elevations corresponded to periodicities with peak-to-peak distances of $0.8-2$ $\mathrm{mm}$ and suggested an arrangement of association and callosal cells in the form of columns (Jones et al., 1975) of 400-1000 $\mu \mathrm{m}$ width. The median spectra of the cell distributions in area 5 were very similar to those of frontal cortex (Fig. 5, c, d). In both the frontal and the parietal cortices the spectra of supraand infragranular callosal and association cells were very similar. Given the injection grids adopted (see Materials and Methods), artifactual periodicities reflecting an uneven distribution of dye at the injection sites would be expected in the range around the 16th Fourier frequency. Such periodicities were indeed observed in some spectra. However, very little power was contained in this frequency range, indicating a negligible contribution of these false periodicities to the overall shape of the spectrum.

The coherency analysis provided a measure of the degree of 

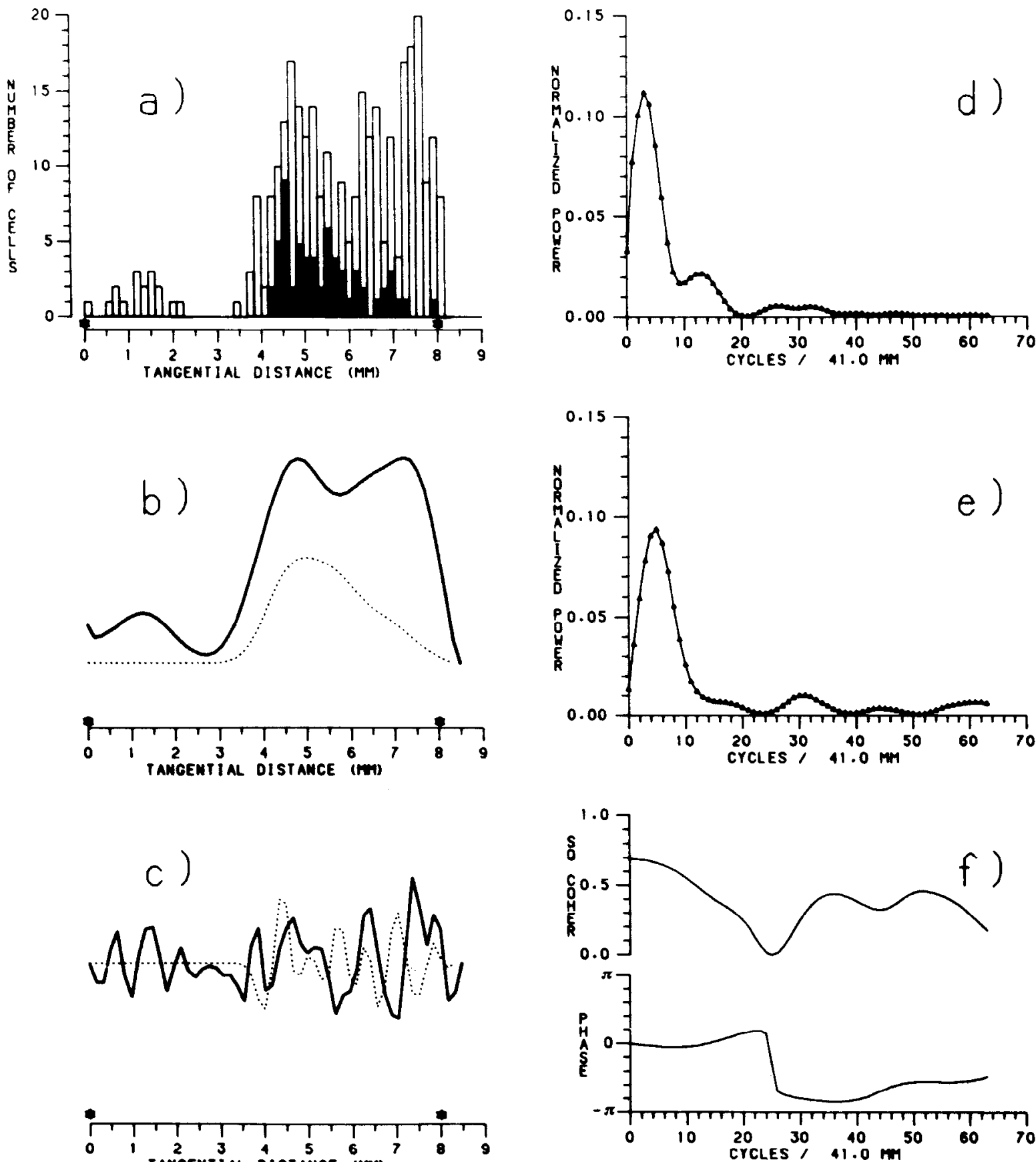

Figure 4. Quantitative analysis for the section shown in Figurc 1. Identical analyses were performed for each section. a, Frequency distributions of callosal ( flled columns) and association (open columns) labeled cells, after flattening the section; bin size is $160 \mu \mathrm{m}$. Asterisks, from left to right, represent the fundus of IPS and the crown of the rostral (upper) bank of IPS. Notice in both distributions a low-frequency component and, superimposed, periodicities at higher frequencies. $b$, Plots of the low-frequency components of the distributions shown in $a$, after high-frequency filtering; here and in $c$, the continuous line refers to association distribution, the dotted line to callosal distribution. $c$, Plots of the high-frequency components of the distributions shown in $a$, after low-frequency filtering. $d$, Power spectrum of the distribution of association cells; notice 2 consistent elevations: the predominant one, with a peak at the 4th Fourier frequency, including the first 20 Fourier frequencies (20 cycles/41 mm), corresponds to periodicities in cell density with a peak-to-peak distance of about $10 \mathrm{~mm}$. Additional smaller elevations, between the 20 th and the 40th Fourier frequencies, correspond to periodicities in cell density with a peak-to-peak distance of more than $1 \mathrm{~mm}$ (i.e., to clusters of about 500 $1000 \mu \mathrm{m}$ width). $e$, Power spectrum of the distribution of callosal cells: the main elevation includes the $1 \mathrm{st} 20$ Fourier frequencies (20 cycles/41 $\mathrm{mm}$ ) and corresponds to periodicities in cell density with a peak-to-peak distance of about $7 \mathrm{~mm}$; periodicities at higher spatial frequencies are included between the 25 th and the 50 th Fourier frequencies and correspond to clusters of about $400-800 \mu \mathrm{m}$ width. $f$, Squared coherency between callosal and association cell distributions (upper curve) and their phase relationships as a function of Fourier frequency (lower curve). Notice the high squared coherency value $(0.79)$ in the domain of the low spatial frequencies, in which callosal and association distributions are very similar, and the lower values of squared coherency at higher spatial frequencies, in which the distributions are less similar. 

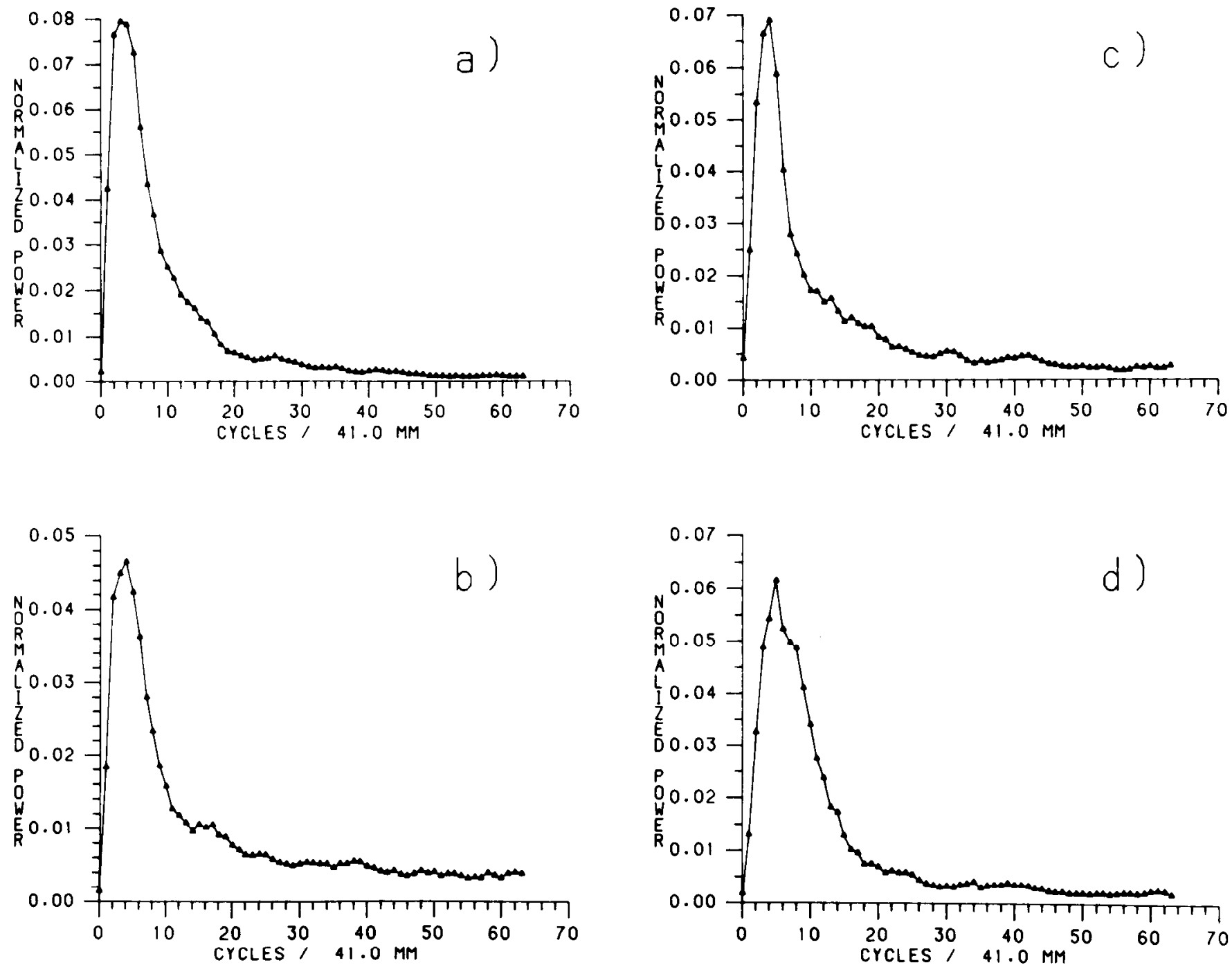

Figure 5. Median estimated spectra of the distributions of $a$, frontal association cells; $b$, frontal callosal cells; $c$, parietal association cells; and $d$, parietal callosal cells. Data refer to distributions of cells labeled in layers II-III. These median spectra reflect only the elevations that were consistent across sections. A predominant elevation in the domain of the low spatial frequencies $(<20)$ and additional elevations at higher Fourier frequencies (21-50) were common features of all spectra. For explanations, see text.

similarity of callosal and association cell distributions for given ranges of frequencies. Squared coherency values from an array of individual sections are shown in the frontal lobe in 3-D plots comparing supra- and infragranular distributions of association cells (Fig. 6). At the range of frequencies $(<20)$ corresponding to the arrangement of these cells in the form of bands, the comparison between supra- and infragranular association cells resulted in the highest coherency value of this study throughout most of the mediolateral extent of the frontal lobe (Fig. 6). In the same range of frequencies, the mean squared coherency value was 0.52 , indicating a high degree of similarity between supra- and infragranular bands of frontal association cells. At this range of frequencies, the phase relation between these distributions was equal to zcro. Wc can conclude that in arcas 4 and 6 the bands of association neurons projecting to area 5 from supra- and infragranular layers were not only very similar but also in register in the rostrocaudal tangential domain. In addition, the Fourier analysis showed that some power was contained in the median estimated spectra at the range of frequen- cies $(21-50$ cycles $/ 41 \mathrm{~mm})$ corresponding to an arrangement of these efferent cells in the form of "columns." In this range the coherency values dropped dramatically in most sections studied - as reflected by the mean squared coherency value $(0.12)-$ suggesting a lack of similarity between columns of association cells in the supra- and infragranular layers; qualitative observations on individual sections support the same conclusion. Because phase values are meaningless in the absence of coherency, no conclusions can be drawn about the degree of overlap of these clusters across layers.

Comparison of callosal and association cell distributions in frontal areas resulted in very low coherency values at all frequency ranges of interest and in most of the investigated cortex (Fig. 7). The mean squared coherency value was less than 0.1 at all frequencies. This indicates that, in areas 4 and 6 , bands and columns of callosal and association cells are distributed independently without any obvious and regular phase relation between them.

At the Fourier frequencies relating to the cell bands, coherency 


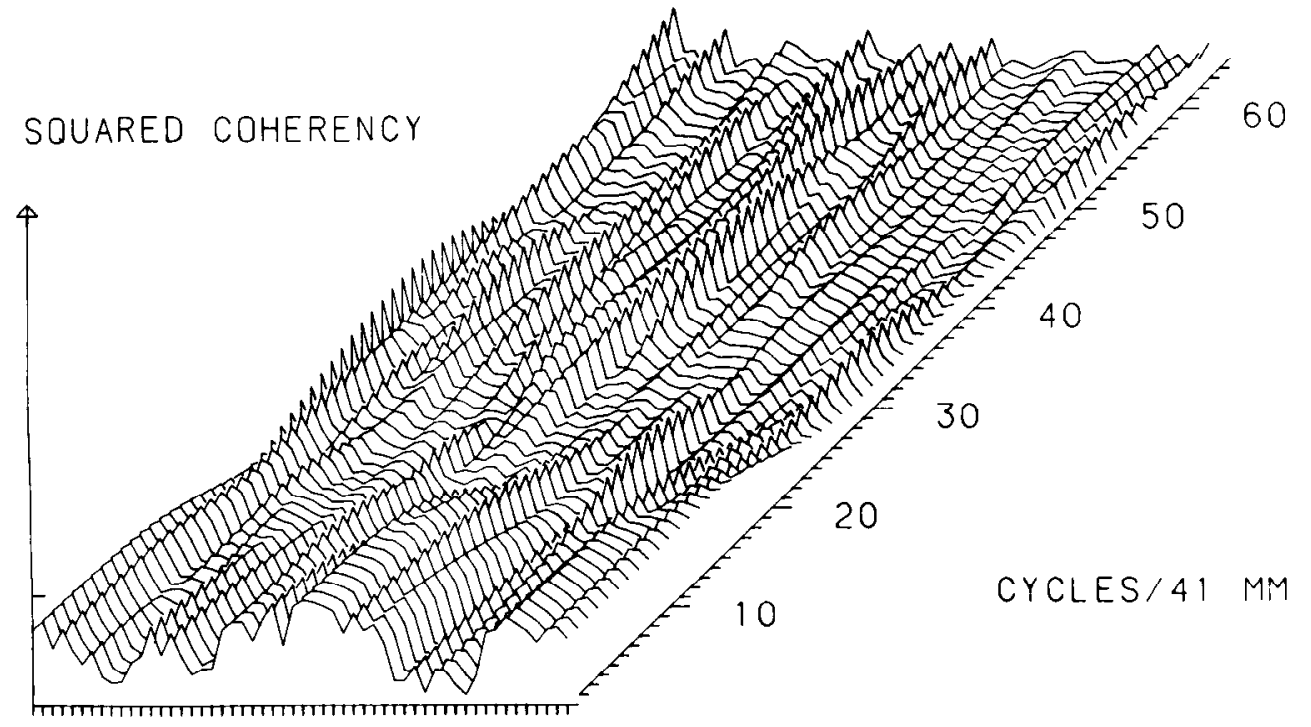

LATERAL

MED I AL values were higher in area 5 than were those observed in the frontal lobe, although regional variations did exist (Fig. 8). This was reflected in a higher value of mean squared coherency $(0.31)$. The phase in this range was equal to zero, suggesting that callosal and association cell bands had an intermediate degree of similarity and spatial match. In the columnar range of periodicities the mean squared coherency value dropped below 0.2 , making impossible any analysis of the phase relations between callosal and association cell columns.

\section{Discussion}

\section{Laminar organization}

No evidence was found in this study of a laminar segregation of callosal versus association neurons in areas 4,6 , and 5. Both populations of corticocortical cells were represented by pyramidal neurons of layers III and pyramidal and fusiform cells of layers V-VI. These findings are in agreement with those obtained in the prefrontal cortex (Schwartz and Goldman-Rakic, 1984) and in area 7a (Andersen et al., 1985). However, significant regional differences were evident in the relative contribution of supra- and infragranular layers to the callosum. In the frontal cortex, callosal neurons were almost equally distributed within supra- and infragranular laminae, whereas in the parietal cortex they predominated in the supragranular layers. This high contribution of infragranular frontal layers, particularly of layer $\mathrm{V}$, to the callosum has also been observed by others (Zant and Strick, 1978). Double-labeling experiments in the rat motor cortex (Catsman-Berrevoets et al., 1980) showed the absence of cortical cells bifurcating to the spinal cord and the contralateral cortex. Therefore, callosal neurons found in layer $\mathrm{V}$ in our study probably were not corticospinal neurons with axon collaterals projecting to the other hemisphere. The relevant contribution

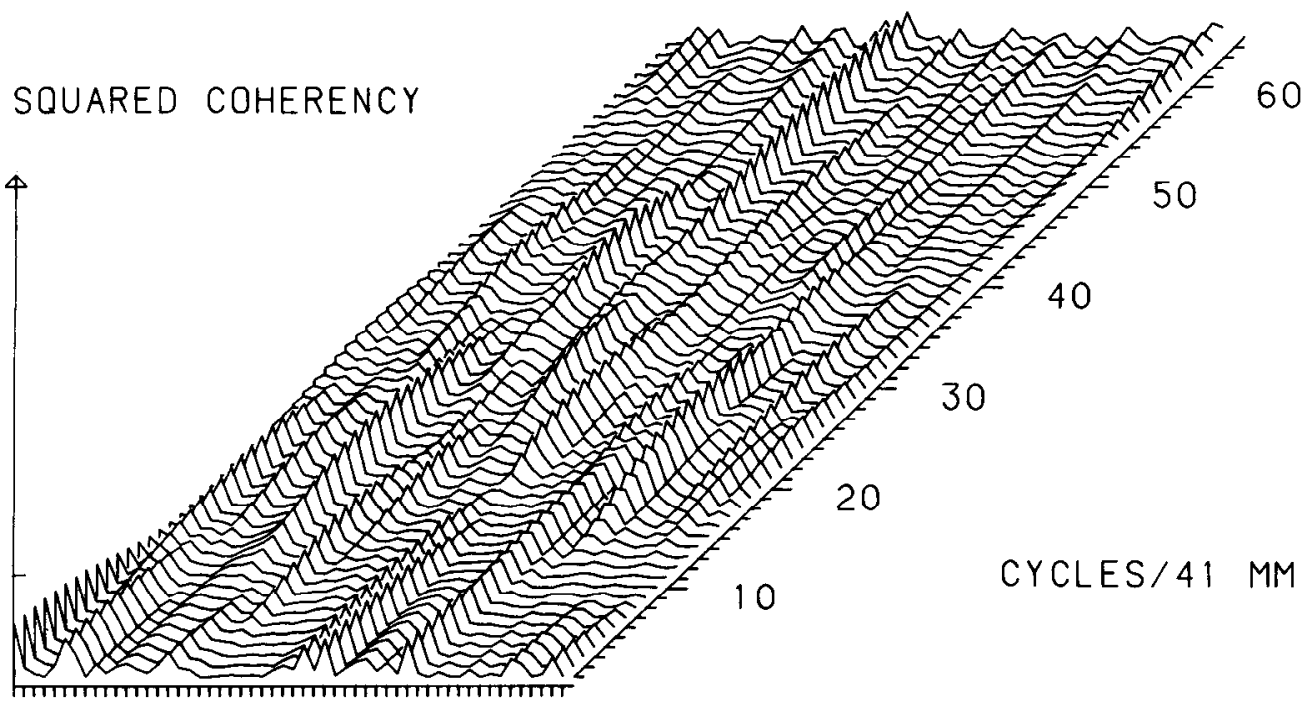

LATERAL

MED I AL
Figure 7. Squared coherency values between association and callosal cell distributions labeled in layer III of the frontal cortex. Notice that coherency values are low in most of the mediolateral extent of the cortex and at almost all Fourier frequencies. This indicates that callosal and association neurons are differently and independently distributed in the tangential cortical domain. For further explanations, see text. 
Figure 8. Pseudo-3-dimensional plot of coherency values as a function of Fourier frequency for an array of sagittal sections of area 5. Data refer to coherency between the distributions of callosal and association cells labeled in layer III. For explanations, see text.

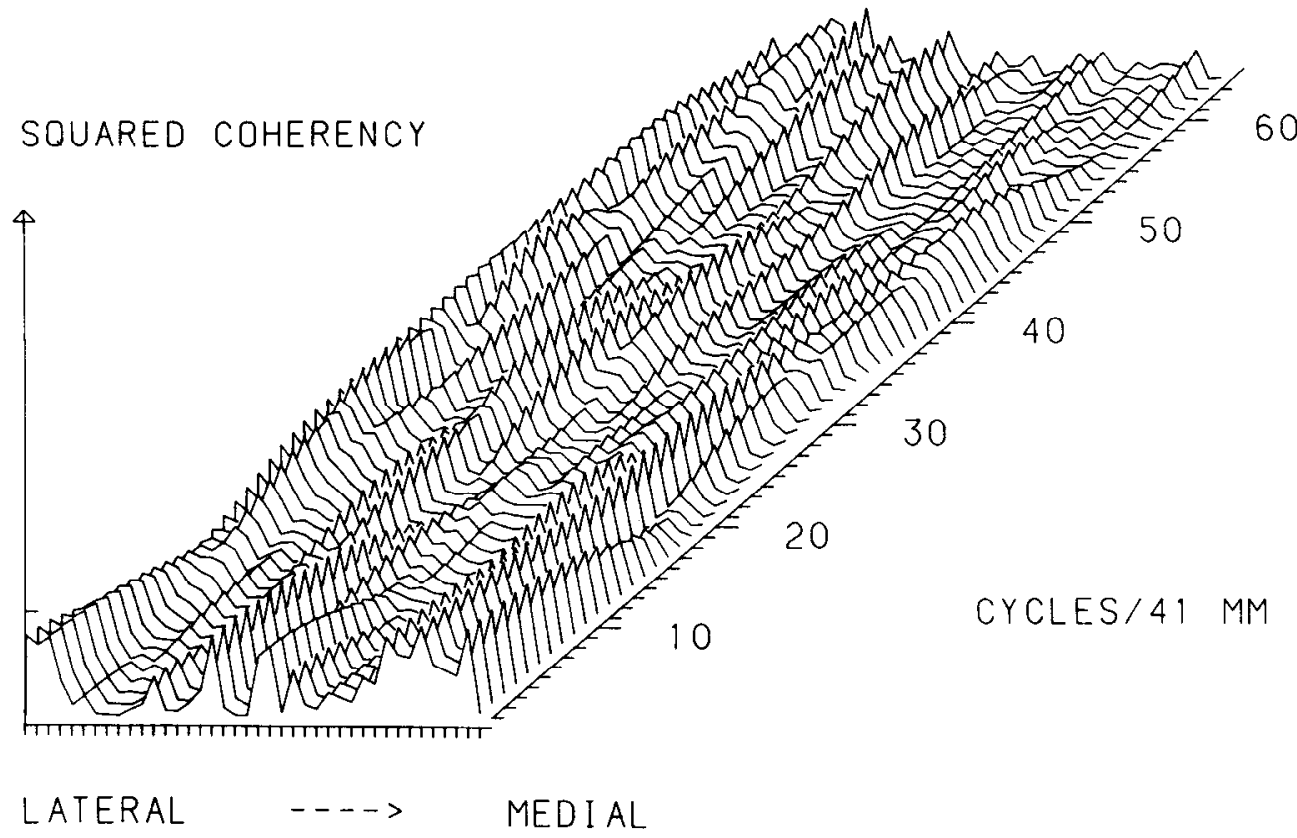

of infragranular frontal cells to the callosum could be related to the special role of layer $\mathrm{V}$ as the main output layer of motor fields to the spinal cord. The presence of callosal neurons in layer $\mathrm{V}$ could provide the basis for a hypothetical mechanism aimed at minimizing possible mismatches between the spinal and the interhemispheric messages.

The laminar distribution of association cells in the frontal areas was very similar to that found in the parietal cortex, which was in agreement with data on the reciprocal association connection between the prefrontal cortex and area 7a of the macaque (Schwartz and Goldman-Rakic, 1984; Andersen et al., 1985) and suggests the absence of a hierarchical relationship between the frontal and parietal fields examined in this study.

\section{Lack of bifurcated neurons}

The callosal and association neurons labeled in areas 4, 6, and 5 had a similar morphology and laminar distribution. Nevertheless, the number of neurons bifurcating ipsi- and contralaterally was extremely low, as evidenced by the very small percentage (less than 1\%) of double-labeled cells. The fact that callosal and association neurons are different neuronal populations seems to be a general rule: similar results were obtained in the prefrontal (Schwartz and Goldman-Rakic, 1984) and posterior parietal (Andersen et al., 1985) cortices of monkey, in auditory (Wong and Kelly, 1981) and somatosensory (Graziosi et al., 1982) cortices of cat, and in limbic areas (Sarter and Markowitsch, 1985) of rat. An exception to this rule was reported by Segraves and Innocenti (1985), who found that about $15 \%$ of the callosal neurons of the suprasylvian area of cat that projected to contralateral areas 17 and 18 also projected to ipsilateral areas 17 and 18. The available data indicate that callosal projecting neurons also avoid direct communication through axonal bifurcations with subcortical structures (Catsman-Berrevoets et al., 1980; Herron and Miller, 1983; Weber et al., 1983). This feature of callosal neurons does not seem to apply to other classes of cortical efferent cells, as about $60 \%$ of corticospinal neurons in the monkey's somatosensory cortex issue axon collaterals to the cuneate nucleus of the same side (Bentivoglio and Rustioni, 1986).

Tangential organization of callosal and association neurons in frontal and parietal cortices

In the frontal and parietal cortices the cells of origin of callosal and association pathways are organized in bands of various shapes and orientations. In the spectral analysis their presence is indicated by dominant periodicities in cell density of more than $4 \mathrm{~mm}$. Callosal and association bands were observed to run from medial to lateral and were formed by discrete clusters of cells. This discrete organization was evidenced in the power spectra by a very small but consistent elevation, which expresses periodicities in cell density with peak-to-peak distances of $0.8-$ $2 \mathrm{~mm}$. These cell clusters therefore have an average width of about $400-1000 \mu \mathrm{m}$ and may correspond to the commissural and association columns first described by Jones et al. (1975). Very similar results were obtained in a recent study (M. $H$. Harries and D. I. Perret, unpublished observations) in which spectral analysis was used to describe the tangential distribution of temporal association neurons projecting to the ipsilateral parietal cortex.

The existence of an uneven distribution of callosal and association cells implies that the original cortical information is transformed in these frontal and parietal outputs. Similar transformations occur in all the cortical efferent systems studied so far (see Innocenti, 1979, and Caminiti et al., 1985, for a review of the literature). In the frontal cortex the callosal and association messages originate from selected parts of areas 4 and 6 and differ significantly, as evidenced by the quantitative analysis. The low coherency between callosal and association cell distributions substantiates this finding. On the other hand, a high coherency was found between association cells in layers II-III and V-VI and between supra- and infragranular distributions of callosal neurons. This suggests that the information addressed to the target territories remains invariant even though a given efferent message originates from populations of cortical 
neurons segregated in depth. In contrast to areas 4 and 6, callosal and association bands in area 5 showed a certain degree of overlap and therefore a certain similarity. Quantitative analysis revealed a higher value of coherency than that observed in the frontal cortex.

The reciprocal spatial relationships between callosal and association cell clusters represent another interesting finding related to a more discrete level of organization. At the range of frequencies corresponding to these columns, the quantitative analysis showed very little coherency in the frontal and parietal cortices. This could have been expected given the tangential segregation of callosal and association neurons. Coherency analyses in very discrete cortical regions in which both cell populations coexisted showed higher coherency values and phase relationships, suggesting an interdigitation between callosal and association cell columns similar to that described in the prefrontal cortex (Schwartz and Goldman-Rakic, 1984). No simple phase relationship between tangential distributions of callosal and association neurons was found in area $7 \mathrm{a}$ of the inferior parietal lobule (Andersen et al., 1985). In agreement with these observations, our study of area 5 suggests a remarkable uniformity in the structural organization of efferent systems across different cytoarchitectonic and functional fields of the parietal lobe. Together with similar studies in other areas (Schwartz and Goldman-Rakic, 1984; Andersen et al., 1985), our data point out important regional variations in the way callosal and association neurons are distributed and related to each other in the tangential cortical domain.

The differences in the distribution of callosal and association cells can be regarded as a morphological substrate whereby a cortical area addresses different messages to different target territories in the same and in the other hemisphere. Despite these differences, the similar spatial periodicities underlying these distributions reveal the existence of a common organizing principle for different corticocortical pathways.

\section{Callosal and association efferent zones of the frontal and parietal cortices}

The uneven distribution of callosal and association neurons and their organization in bands determine frontal and parietal efferent zones that may play a major role in the shaping of these efferent messages. The exact definition of the specific operations performed within these zones rests on the comparison of distribution patterns of a given class of corticocortical cells with the set of functional properties represented in the cortex. This approach needs to be extended beyond purely somatotopic aspects to other domains of representation of information. It should be adopted not only in the "association" cortices, in which maps of the periphery cannot account for the properties encoded by neuronal populations, but also in cortices that contain fine-grain maps of the periphery, such as primary sensory and motor areas. Let us consider, for instance, the reciprocal frontoparietal connection of this study. Comparison of distributions of association cells and somatotopy in the areas of origin would only reveal a prominent role of information originating in the arm region (see also Strick and Kim, 1978; Zarzecki et al., 1978) in the interplay of frontal and parietal cortices. Beyond this, speculations concerning the functions of this association connection can be made based on neurophysiological studies of the dynamic properties of frontal and parietal neurons (Georgopoulos et al., 1982; Kalaska et al., 1983; Caminiti et al., 1988a). We recently proposed (Caminiti et al., 1985) that the association projection from fron- tal fields to area 5 may represent an anatomical substrate for the transmission to the parietal lobe of information on the coding of direction of movement in space. This suggestion rested on the analysis of functional properties of populations of frontal (Georgopoulos et al., 1982) and parietal (Kalaska et al., 1983) neurons and their temporal relations to movement, and was also supported by behavioral data (Halsband and Passingham, 1982). The study by Kalaska et al. (1983) assigned to area 5 a role of "spatial comparator," in which an efferent copy of a motor command addressed from the frontal fields is contrasted with the dynamic and continuously updated image of movement as it evolves in time. Obviously, the outcome of this comparison must be addressed through the efferent connections of the superior parietal lobule to other stations of that distributed system (Mountcastle, 1978) that control movement in space. The parietofrontal association pathway described in this study may represent a substrate for returning the outcome of this parietal operation to the frontal premotor and motor fields. This would allow a comparison between intention and execution that could be of relevance for corrective mechanisms and subsequent motor behavior.

Similar considerations apply to the callosal connections of frontal and parietal cortices. The callosal system of the superior parietal lobule has been described in detail (Caminiti and Sbriccoli, 1985) and will be reconsidered here only in relation to certain aspects of the interhemispheric transfer of motor behavior. In agreement with other studies, the pattern of frontal callosal connections that emerges from our work points up some of the main features of that transfer: the relative absence of callosal cells in part of the hand and foot representations of M1 (Jenny, 1979; Jones et al., 1979; Killackey et al., 1983; Gould et al., 1986); the presence of callosal connections in more rostrally and laterally located frontal fields (Gould et al., 1986), in which additional representations of the arm and hand have been found (in area 6; Muakkassa and Strick, 1979; Gould et al., 1986; Matelli et al., 1986); the abundance of callosal projecting cells in the proximal limb, trunk, and face representations (Jones et al., 1979; Gould et al., 1986). This complex and fractionated pattern of callosal connections suggests a heterogeneity in the structural organization of the frontal lobe that is also evidenced by morphological studies (Matelli et al., 1986; Barbas and Pandya, 1987). In view of a redefinition of certain functional aspects of frontal motor fields prompted by the demonstration of multiple motor representations (Muakkassa and Strick, 1979; Gould et al., 1986), our study, together with the detailed investigation of Gould et al. (1986), provides a foundation for a new interpretation of the pattern of frontal callosal connectivity. This has been interpreted according to the "midline rule" (see Berlucchi, 1981, and Innocenti, 1986, for a review), based on the observation that regions devoted to distal limb movements were relatively free of callosal connections (Jones and Powell, 1969; Pandya and Vignolo, 1971; Zant and Strick, 1978; Jenny, 1979; Jones et al., 1979; Gould et al., 1986). However, when the distribution of callosal neurons has been combined with microstimulation methods (Matsumara and Kubota, 1979; Gould et al., 1986), callosal connections have been recognized in frontal regions devoted to hand movements, in agreement with previous data by Shanks et al. (1975), Goldman and Nauta (1977), and Jenny (1979). This discrepancy can be explained in part by an interpretation of the callosal connectivity of this region based on a single motor map (Woolsey et al., 1950). It seems, therefore, that certain cortical regions devoted to hand movements are 
relatively free of callosal connections, especially in area 4, whereas other hand representations are rich in them. Our study and that of Gould et al. (1986) together indicate the existence of multiple sources of callosal connections for the interhemispheric transfer of manual motor habits in the frontal lobe. These connections also may provide an anatomical substrate for the representation of ipsilateral hand movements. The existence of neurons related to bilateral hand movements in the premotor cortex (Rizzolatti et al., 1987; Tanji et al., 1987) supports this hypothesis. In this respect, it is worth mentioning that patients who had commissurotomies consistently showed some degree of motor intermanual conflict (Wilson et al., 1977; Bogen, 1979). Furthermore, in tests devised for ipsilateral motor control, these patients were unable to replicate with one hand postures assumed by the other hand (Bogen, 1979) or to mimic with the left hand postures flashed to the left hemisphere (Gazzaniga et al., 1967). Probably more relevant to our discussion is the evidence of long-term motor deficits in split-brain patients, who were unable to perform complex bimanual tasks requiring interdependent sequencing of hand movements (Preilowsky, 1975; Zaidel and Sperry, 1977). It can be affirmed that frontal motor fields, together with the callosal connections originating in the hand representations of S1 and S2 (Caminiti et al., 1979; Manzoni et al., 1984, 1986) and area 5 (Caminiti and Sbriccoli, 1985; and this study), are an important segment of the distributed system that controls intermanual transfer. Beyond the limits imposed by an interprctation of callosal connectivity based on topographical criteria, only physiological studies of the movement parameters encoded by frontal callosal neurons will provide a positive image of the consequences of commissurotomy on motor behavior.

\section{Appendix}

\section{Spectral analysis}

The following steps were used in the calculation of the median normalized estimated spectra presented in this paper:

(1) The cell count data are more likely to have a Poisson than a Gaussian distribution. A square root transformation was used to make the data more Gaussian.

(2) The mean bin value of each section was subtracted from that section to prevent the leakage of a large component at zero frequency from obscuring the low-frequency components.

(3) Split cosine tapering (Bloomfield, 1976) was applied to the initial and final $10 \%$ of each section to further reduce leakage.

(4) Each section was padded with zeroes to bring all sections to the standard length of $41 \mathrm{~mm}$ ( $256 \mathrm{bins})$ for the purpose of Fourier transformation.

(5) A fast Fourier transform (FFT) algorithm was used to calculate the discrete Fourier transform (DFT) of the data.

(6) The periodogram was calculated by squaring the magnitude of the DFT.

(7) The estimated spectrum was calculated by smoothing the periodogram with one pass of a seven-point (1234321) moving average.

(8) The normalized estimated spectrum was calculated by dividing each point of the estimated spectrum by the integral of the entire spectrum.

(9) For each Fourier frequency, the median across all the normalized estimated spectra in a hemisphere was calculated. The collection of these median values was called the median spectrum.

\section{Coherency analysis}

If $\mathrm{Y}_{\mathrm{km}}$ is the transformed, tapered, zero-padded cell count for bin $t$ of a cell population $m$ along section $k$, then the DFT of the series $\mathrm{Y}_{k m}$, $\mathrm{d}_{k m}\left(\omega_{j}\right)$, is defined as

$$
\mathbf{d}_{k m}\left(\omega_{j}\right)=\sum_{i=0}^{\mathrm{n}-1} \mathbf{Y}_{k m t} \mathbf{e}^{-i \omega j t}, j=0,1,2, \ldots, \mathbf{n} / 2
$$

where $\omega_{j}=2 \pi j / \mathrm{n}$ is the $j$ th Fourier frequency and $\mathrm{n}$ is the standardized number of observations along each section. The DFT is a complex number whose real and imaginary parts represent the coefficients of cosine and sine waves, respectively, the sum of which has been leastsquared fit to the data $Y_{k m}$.

The autoperiodogram, $\mathrm{F}_{k m}\left(\omega_{j}\right)$, of $\mathrm{Y}_{k m}$ is defined as

$$
\mathrm{F}_{k m}\left(\omega_{j}\right)=2 \pi / \mathrm{n}\left|\mathrm{d}_{k m}\left(\omega_{j}\right)\right|^{2} .
$$

The autoperiodogram is real valued, and, when smoothed, provides an estimate, $\mathrm{f}_{k m}\left(\omega_{i}\right)$, of the spectrum of $\mathbf{Y}_{\mathrm{km}}$.

The cross periodogram, $\mathrm{G}_{k}\left(\omega_{j}\right)$, between cell populations 1 and 2 of section $k$ is defined by

$$
\mathrm{G}_{k}\left(\omega_{j}\right)=2 \pi / \mathrm{nF}_{k /}\left(\omega_{j}\right) \mathrm{F}_{k 2}^{*}\left(\omega_{j}\right)
$$

where the asterisk indicates the operation of complex conjugation. The cross periodogram is not, in general, real valued. Thus, when smoothed (real and imaginary parts being smoothed separately), the resultant estimated cross spectrum, $g_{k}\left(\omega_{j}\right)$, is also complex valued.

The magnitude of the cross spectrum, $\left|g_{k}\left(\omega_{j}\right)\right|$, is a measure of the extent to which there are oscillations in the 2 series with constant phase. In general, it is more convenient to normalize the magnitude of the cross spectrum by the square root of the product of the individual autospectra to arrive at the coherency, $\mathrm{s}_{k}\left(\omega_{j}\right)$, defined as

$$
\mathbf{s}_{k}\left(\omega_{j}\right)=\frac{\left|g_{k}\left(\omega_{j}\right)\right|}{\left[\mathrm{f}_{k 1}\left(\omega_{j}\right) \mathbf{f}_{k 2}\left(\omega_{j}\right)\right]^{1 / 2}} .
$$

Because the cross spectrum is smaller than or equal to the product of the individual autospectra at all frequencies, the coherency varies between zero and 1 . A coherency value of 1 indicates a complete linear dependency between the 2 series. A value of zero indicates no dependence. Often, as in our case, we were interested in high values of coherency. For this reason we have used the squared coherency, $\mathbf{s}_{k}{ }^{2}\left(\omega_{j}\right)$, which tends to deemphasize low coherency values. The phase of the cross spectrum is of interest when the coherency indicates a region of constant phase relationship. We have followed standard practice by presenting the phase of the cross spectrum along with the plot of coherency (see Fig. 4; Bloomfield, 1976).

Smoothing is an integral part of any coherency calculation. In the computations of the auto- and cross spectra used to derive coherency, we used 3 passes of a 13-point modified Daniell filter (Bloomfield, 1976).

To measure those features of the coherency that were present throughout all sections, we calculated the mean squared coherency, $\mathrm{s}^{2}\left(\omega_{j}\right)$, defined by

$$
\mathbf{s}^{2}\left(\omega_{j}\right)=1 / \mathrm{N} \sum_{k=1}^{\mathrm{N}} \mathrm{s}_{k}^{2}\left(\omega_{j}\right)
$$

where $\mathrm{N}$ is the number of sections in that hemisphere. The associated phase, $\phi\left(\omega_{j}\right)$, was computed as the phase of the complex number $\mathbf{P}$,

$$
\mathrm{P}\left(\omega_{j}\right)=\sum_{k=1}^{\mathrm{N}} \cos \left[\varphi_{k}\left(\omega_{j}\right)\right]+\mathrm{i} \sum_{k=1}^{\mathrm{N}} \sin \left[\varphi_{k}\left(\omega_{j}\right)\right],
$$

where $\mathrm{N}$ is the number of sections and $\varphi_{k}\left(\omega_{j}\right)$ is the phase of the estimated cross spectrum $\mathrm{g}_{k}\left(\omega_{j}\right)$.

\section{References}

Andersen, R. A., C. Asanuma, and M. W. Cowan (1985) Callosal and prefrontal associational projecting cell populations in area $7 \mathrm{a}$ of the Macaque monkey: A study using retrogradely transported fluorescent dyes. J. Comp. Neurol. 232: 443-455.

Barbas, H., and D. N. Pandya (1987) Architecture and frontal cortical connections of the premotor cortex (area 6) in the rhesus monkey. J. Comp. Neurol. 256: 211-228.

Bentivoglio, M., and A. Rustioni (1986) Corticospinal neurons with branching axons to the dorsal column nuclei in the monkey. J. Comp. Neurol. 253: 260-276.

Berlucchi, G. (1981) Recent advances in the analysis of the neural substrates of interhemispheric communication. In Brain Mechanisms and Perceptual Awareness, O. Pompeiano and C. Ajmone Marsan, eds., pp. 132-152, Raven, New York. 
Bloomfield, P. (1976) Fourier Analysis of Time Series: An Introduction Wiley, New York.

Bogen, E. G. (1979) The callosal syndrome. In Clinical Neuropsychology, K. M. Heilman and E. Valenstein, eds., pp. 308-359, Oxford U. P., New York.

Caminiti, R., and A. Sbriccoli (1985) The callosal system of the superior parietal lobule in the monkey. J. Comp. Neurol. 237: 85-99.

Caminiti, R., G. M. Innocenti, and T. Manzoni (1979) The anatomical substrate of callosal messages from SI and SII in the cat. Exp. Brain Res. 35: 295-314.

Caminiti, K., S. Zeger, P. B. Johnson, A. Urbano, and A. P. Georgopoulos (1985) Cortico-cortical efferent systems in the monkey: A quantitative spatial analysis of the tangential distribution of cells of origin. J. Comp. Neurol. 241: 405-419.

Caminiti, R., P. B. Johnson, R. A. Pastore, and A. Urbano (1988a) Spatial coding of movement direction in frontal cortical areas. Soc. Neurosci. Abstr. 14: 342.

Caminiti, R., P. B. Johnson, A. Urbano, A. P. Georgopoulos, and S. Zeger (1988b) Callosal and association neurons in the cortical space. Behav. Brain Res. 30: 193-201.

Catsman-Berrevoets, C. E., R. N. Lemon, C. A. Verburgh, M. Bentivoglio, and H. G. J. M. Kuypers (1980) Absence of callosal collaterals derived from rat corticospinal neurons. A study using fluorescent retrograde tracing and electrophysiological techniques. Exp. Brain Res. 39: 433-440.

Chow, K. L., H. D. Baumbach, and R. Lawson (1981) Callosal projections of the striate cortex in the neonatal rabbit. Exp. Brain Res. 42: 122-126.

Clark, R. W., and E. S. Luschei (1974) Short latency jaw movements produced by low intensity intracortical microstimulation of the precentral face area in the monkey. Brain Res. 70: 144-147.

Feng, J. Z., and J. F. Brugge (1983) Postnatal development of auditory callosal connections in the kitten. J. Comp. Neurol. 214: 416-426.

Fitzpatrick, K. A., and T. J. Imig (1980) Auditory cortico-cortical connections in the owl monkey. J. Comp. Neurol. 192: 589-610.

Gazzaniga, M. S., J. Bogen, and R. W. Sperry (1967) Dyspraxia following division of cerebral commissures. Arch. Neurol. 16: 600-612.

Georgopoulos, A. P., J. F. Kalaska, R. Caminiti, and J. T. Massey (1982) On the relations between the direction of two-dimensional arm movements and cell discharge in primate motor cortex. J. Neurosci. 2: $1527-1537$.

Goldman, P. S., and W. J. M. Nauta (1977) Columnar distribution of cortico-cortical fibres in the frontal association, limbic, and motor cortex of the developing rhesus monkey. Brain Res. 122: 393-413.

Goldman-Rakic, P. S., and M. L. Schwartz (1982) Interdigitation of contralateral and ipsilateral columnar projections to frontal association cortex in primates. Science 216: 755-757.

Gould, H. J., C. G. Cusik, T. P. Pons, and J. H. Kaas (1986) The relationship of corpus callosum connections to electrical stimulation maps of motor, supplementary motor, and frontal eye fields in the owl monkey. J. Comp. Neurol. 247: 297-325.

Graziosi, M. E., E. Tucci, P. Barbaresi, G. Ugolini, and T. Manzoni (1982) Cortico-cortical neurons of somesthetic area SI as studied in the cat with fluorescent retrograde double-labeling. Neurosci. Lett. 31: $105-110$.

Gross, C. G., and M. Mishkin (1977) The neural basis of stimulus equivalence across retinal translation. In Lateralization in the Nervous System, S. Harnard, R. W. Doty, L. Goldstein, J. Jaynes, and G. Krauthamer, eds., pp. 109-122, Academic, New York.

Halsband, V., and R. Passingham (1982) The role of premotor and parietal cortex in the direction of action. Brain Res. 240:91-105.

Herron, P., and J. Miller (1983) The interrelation of callosal and corticospinal neurons in the sensorimotor region of the rat. Neurosci. Abstr. 9: 493.

Hubel, D. H., and T. N. Wiesel (1967) Cortical and callosal connections concerned with the vertical meridian of the visual fields in the cat. J. Neurophysiol. 30: 1561-1573.

Innocenti, G. M. (1979) A hypothesis on the efferent systems from the visual cortex. In Developmental Neurobiology of Vision, R. D. Freeman, ed., pp. 227-234, Plenum, New York.

Innocenti, G. M. (1980) The primary visual pathway through the corpus callosum: Morphological and functional aspects in the cat. Arch. it. Biol. 118: 124-188.

Innocenti, G. M. (1986) The general organization of callosal connections. In Cerebral Cortex, Vol. 5, Sensory-Motor Areas and Aspects of Cortical Connectivity, E. G. Jones and A. Peters, eds., pp. 291353, Plenum, New York

Innocenti, G. M., and R. Caminiti (1980) Postnatal shaping of callosal connections from sensory areas. Exp. Brain Res. 38: 381-394.

Innoccnti, G. M., and S. Clarkc (1984) Bilatcral transitory projections to visual areas from auditory cortex in kittens. Dev. Brain Res. 14: 143-148.

Innocenti, G. M., L. Fiore, and R. Caminiti (1977) Exuberant projections into the corpus callosum from the visual cortex of newborn cats. Neurosci. Lett. 4: 237-242.

Ivy, G. O., and H. P. Killackey (1982) Ontogenetic changes in the projections of neocortical neurons. J. Neurosci. 2: 735-743.

Jenny, A. B. (1979) Commissural projections of the cortical hand motor area in monkeys. J. Comp. Neurol. 188: 137-146.

Jones, E. G., and T. P. S. Powell (1969) Connexions of the somatic sensory cortex of the rhesus monkey. Contralateral cortical connexions. Brain 92: 717-730.

Jones, E. G., H. Burton, and R. Porter (1975) Commissural and cortico-cortical "columns" in the somatic sensory cortex of primates. Science 190: 572-574.

Jones, E. G., J. D. Coulter, and S. P. Wise (1979) Commissural columns in the sensory-motor cortex of monkeys. J. Comp. Neurul. 188. 113-136.

Kalaska, J. F., R. Caminiti, and A. P. Georgopoulos (1983) Cortical mechanisms related to direction of two-dimensional arm movements: Relations in parietal area 5 and comparison with motor cortex. Exp. Brain Res. 51: 247-260.

Killackey, H. P., and L. M. Chalupa (1986) Ontogenetic change in the distribution of callosal projecting neurons in the postcentral gyrus of fetal rhesus monkeys. J. Comp. Neurol. 244: 331-348.

Killackey, H. P., H. J. Gould, C. G. Cusik, T. P. Pons, and J. H. Kaas (1983) The relation of corpus callosum connections to architectonic fields and body surface maps in sensorimotor cortex of new and old world monkeys. J. Comp. Neurol. 219: 384-419.

Kunzle, H. (1976) Alternating afferent zones of high and low axon terminal density within the macaque motor cortex. Brain Res. 106. 365-370.

Manzoni, T., P. Barbaresi, and F. Conti (1984) Callosal mechanisms for the interhemispheric transfer of hand somatosensory information in the monkey. Behav. Brain Res. 11: 155-170.

Manzoni, T., F. Conti, and M. Fabri (1986) Callosal projections from area SII to SI in monkeys. Anatomical organization and comparison with association projections. J. Comp. Neurol. 252: 245-263.

Matelli, M., R. Camarda, M. Glickstein, and G. Rizzolatti (1986) Afferent and efferent projections of the inferior area 6 in the macaque monkeys. J. Comp. Neurol. 251: 281-298.

Matsumara, M., and K. Kubota (1979) Cortical projection to handarm motor area from post-arcuate area in macaque monkeys: A histological study of retrograde transport of horseradish peroxidase. Neurosci. Letl. 11: 241-246.

McGuinnes, E., D. Siversten, and J. M. Allman (1980) Organization of the face representation in the macaque motor cortex. J. Comp. Neurol. 193: 591-608.

Mountcastle, V. B. (1978) An organizing principle for cerebral function: The unit module and the distributed system. In The Mindful Brain: Cortical Organization and the Group Selective Theory of Higher Brain Functions, G. M. Edelman and V. B. Mountcastle, eds., pp. $7-$ 50, MIT Press, Cambridge, MA.

Muakkassa, K. F., and P. L. Strick (1979) Frontal lobe inputs to primate motor cortex: Evidence for four somatotopically organized "premotor" areas. Brain Res. 177: 176-182.

Pandya, D. N., and L. Vignolo (1971) Intra- and interhemispheric projections of the precentral, premotor and arcuate areas in the rhesus monkeys. Brain Res. 26: 217-233.

Preilowsky, B. F. B. (1975) Bilateral motor interaction: Perceptualmotor performance of partial and complete "split-brain" patients. In Cerebral Localization, K. Zulch, O. Creutzfeldt, and G. C. Galbraith, eds., pp. 115-132, Springer, Berlin.

Rakic, P. (1974) Neurons in rhesus monkey visual cortex: Systematic relation between time of origin and eventual disposition. Science 183: $425-427$.

Rizzolatti, G., M. Gentilucci, L. Fogassi, G. Luppino, M. Matelli, and S. Ponzoni-Maggi (1987) Neurons related to goal-directed motor acts in inferior area 6 of the macaque monkey. Exp. Brain Res. 67: $220-224$ 
Rockland, K. S., and D. N. Pandya (1979) Laminar origins and terminations of cortical connections of the occipital lobe in the rhesus monkey. Brain Res. 179: 3-20.

Sarter, M., and H. J. Markowitsch (1985) Convergence of intra- and interhemispheric cortical afferents: Lack of collateralization and evidence for a subrhinal cell group projecting heterotopically. J. Comp. Neurol. 236: 283-296.

Schwartz, M. L. K., and P. S. Goldman-Rakic (1984) Callosal and intrahemispheric connectivity of the prefrontal association cortex in rhesus monkey: Relation between intraparietal and principal sulcal cortex. J. Comp. Neurol. 226: 403-420.

Segraves, M. A., and G. M. Innocenti (1985) A comparison of the distribution of ipsilaterally and contralaterally projecting cortico-cortical neurons in cat visual cortex using fluorescent tracers. J. Neurosci. 5: 2107-2118.

Sessle, B. J., and M. Wiesendanger (1982) Structural and functional definition of the motor cortex in the monkey (Macaca fascicularis). J. Physiol. (Lond.) 323: 245-265.

Shanks, M. F., A. J. Rockel, and T. P. S. Powell (1975) The commissural fibre connections of the primary somatic sensory cortex. Brain Res. 98: 166-171.

Strick, P. L., and C. C. Kim (1978) Input to primate motor cortex from posterior parietal cortex (area 5). I. Demonstration by retrograde transport. Brain Res. 157: 325-330.

Tanji, J., K. Okano, and K. C. Sato (1987) Relations of neurons in the non primary motor cortex to bilateral hand movements. Nature 327: 618-620.

Van Essen, D. C., W. T. Newsome, and J. L. Bixby (1982) The pattern of interhemispheric connections and its relationship to extrastriate visual areas in the macaque monkey. J. Neurosci. 2: 265-283.

Weber, J. T., R. W. Rieck, and H. J. Gould (1983) Interhemispheric and subcortical collaterals of single cortical neurons in the adult cat. Brain Res. 276: 333-338.

Wilson, D. H., A. Reeves, M. Gazzaniga, and C. Culver (1977) Cerebral commissurotomy for control of intractable seizures. Neurology 27: $708-715$

Wong, D., and J. P. Kelly (1981) Differentially projecting cells in individual layers of the auditory cortex: A double-labeling study. Brain Res. 230: 362-366.

Wong-Riley, M. T. T. (1979) Columnar cortico-cortical interconnections within the visual system of the squirrel and macaque monkey, Brain Res. 162: 201-217.

Woolsey, C. N., P. H. Settlage, D. R. Meyer, W. Spencer, T. M. Hamuy, and A. M. Travis (1950) Patterns of localization in precentral and "supplementary" motor area and their relations to the concept of a premotor area. Res. Publ. Ass. Rev. Nerv. Ment. Dis. 30: 238-264. Zaidel, J. D., and R. W. Sperry (1977) Some long-term motor effects of cerebral commissurotomy in man. Neuropsychologia 15:193-204.

Zant, J. D., and P. L. Strick (1978) The cells of origin of interhemispheric connections in the primate motor cortex. Neurosci. Abstr. 4: 308.

Zarzecki, P., P. L. Strick, and H. Asanuma (1978) Input to primate motor cortex from posterior parietal cortex (area 5). II. Identification by antidromic activation. Brain Res. 157: 331-335.

Zeki, S. M. (1978) The cortical projections of foveal striate cortex in the rhesus monkey. J. Physiol. 277: 227-244. 